\title{
Cold shock Y-box protein-1 proteolysis autoregulates its transcriptional activities
}

\author{
Claudia RC van Roeyen ${ }^{1+}$, Florian G Scurt ${ }^{2 \dagger}$, Sabine Brandt ${ }^{2}$, Vanessa A Kuhl', Sandra Martinkus ${ }^{1}$, Sonja Djudjaj ${ }^{2}$, \\ Ute Raffetseder ${ }^{1}$, Hans-Dieter Royer ${ }^{3}$, Ioannis Stefanidis ${ }^{4}$, Sandra E Dunn ${ }^{5}$, Steven Dooley ${ }^{6}$, Honglei Weng ${ }^{6}$, \\ Thomas Fischer ${ }^{7}$, Jonathan A Lindquist ${ }^{2}$ and Peter R Mertens ${ }^{2^{*}}$
}

\begin{abstract}
Background: The Y-box protein-1 (YB-1) fulfills pleiotropic functions relating to gene transcription, mRNA processing, and translation. It remains elusive how YB-1 shuttling into the nuclear and cytoplasmic compartments is regulated and whether limited proteolysis by the 205 proteasome releases fragments with distinct function(s) and subcellular distribution(s).

Results: To address these questions, mapping of domains responsible for subcellular targeting was performed. Three nuclear localization signals (NLS) were identified. NLS-1 (aa 149-156) and NLS-2 (aa 185-194) correspond to residues with unknown function(s), whereas NLS-3 (aa 276-292) matches with a designated multimerization domain. Nuclear export signal(s) were not identified. Endoproteolytic processing by the 205 proteasome before glycine 220 releases a carboxy-terminal fragment (CTF), which localized to the nucleus, indicating that NLS-3 is operative. Genotoxic stress induced proteolytic cleavage and nuclear translocation of the CTF. Co-expression of the CTF and full-length YB-1 resulted in an abrogated transcriptional activation of the MMP-2 promoter, indicating an autoregulatory inhibitory loop, whereas it fulfilled similar trans-repressive effects on the collagen type I promoter.

Conclusion: Compartmentalization of YB-1 protein derivatives is controlled by distinct NLS, one of which targets a proteolytic cleavage product to the nucleus. We propose a model for an autoregulatory negative feedback loop that halts unlimited transcriptional activation.
\end{abstract}

Keywords: Cold shock protein, DbpB, YBX1, Nuclear localization signal, Post-translational modification, RNA/DNA binding protein

\section{Background}

Cold shock proteins (CSP) are amongst the most conserved proteins in evolution, sharing a cold shock domain (CSD) from pro- to eukaryotes [1]. Numerous functions have been unravelled for members of this protein family. In bacteria CSPs are co-ordinately up-regulated following a decrease in temperature to rescue bacterial growth [2]. In eukaryotic cells CSPs are involved in the transcriptional regulation of genes related to cell proliferation (e.g. DNA polymerase- $\alpha$ [3], cyclins A and B1 [4], FAS receptor [5]). Further target genes coordinate matrix synthesis and

\footnotetext{
*Correspondence: peter.mertens@med.ovgu.de

${ }^{\dagger}$ Equal contributors

2Department of Nephrology and Hypertension, Diabetes and Endocrinology, Otto-von-Guericke University Magdeburg, Leipziger Str 44, 39120 Magdeburg, Germany

Full list of author information is available at the end of the article
}

degradation [6], inflammatory responses (e.g. IL-2 [7], GM-CSF [8]), and antigen presentation (major human leukocyte antigen [9], $\mathrm{ABC}$ transporters [10]).

Y-box protein (YB)-1 is the prototypic member of the cold shock protein family in humans. YB-1 acts in a cellcontext specific manner on gene transcription, e.g. of matrix-metalloproteinase (MMP)-2 [11] and granulocyte macrophage-colony stimulating factor (GM-CSF) genes [8]. Furthermore, YB-1 has been isolated as a major component of messenger ribonucleoprotein particles (mRNPs) that guide mRNA storage, for instance of GM-CSF [12] and renin [13], and is involved in translation processes [14-16]. The specific association of YB-1 with mRNA evidenced its regulatory role in mRNA processing in concert with splicing factors, such as SRp30c [17].

\section{Biomed Central}

(c) 2013 van Roeyen et al.; licensee BioMed Central Ltd. This is an Open Access article distributed under the terms of the Creative Commons Attribution License (http://creativecommons.org/licenses/by/2.0), which permits unrestricted use, distribution, and reproduction in any medium, provided the original work is properly cited. 
The plethora of functions fulfilled by YB-1 necessitates subcellular protein shuttling with high stringency. Specific protein domains, denoted nuclear export signals (NES) and nuclear localization signals (NLS), may coordinate such multifunctional shuttling and tasking [18]. Coordinated YB-1 protein shuttling has been characterized with in vitro cell models. Cell stress exerted by hyperthermia [19], cytotoxic agents [20], and ultraviolet irradiation [20] alters a predominant cytoplasmic YB-1 localization in unstressed cells to a nuclear preponderance. Cytokines IL-2 $[21]$ and IFN- $\gamma[6,22]$ are also reported to induce a similar nuclear shuttling. In vivo data have been mostly collected with cancer tissue. YB-1 has been detected in the cytoplasmic and/or nuclear compartments [23,24]. Nuclear YB-1 localization has been described as a negative prognostic marker for cancers of the breast [25], prostate [26], synovia [23,26], and lung [24]. Discussions have focused on the underlying mechanism(s) for poor cancer prognosis, e.g. the chemotherapy insensitivity of cells with high levels of nuclear YB-1 expression may be due to upregulated expression of multidrug resistance-1 (MDR-1 [10]) and the ABC transporter MRP2 [27].

Given the aforementioned tightly regulated subcellular distribution of YB-1 in inflammatory diseases and cancer, the present study was initiated to elaborate the underlying mechanisms that orchestrate YB-1 protein shuttling. Firstly, differences in subcellular targeting of fluorescently-tagged YB-1 domains was assessed in vitro using laser scanning microscopy [4]. Additionally, nuclear localization signals (NLS) that target domains of the protein, e.g. following endoproteolysis, to the nuclear compartment were fine-mapped. The functional relevance of a predefined carboxy-terminal fragment (CTF), that readily shuttles to the nuclear compartment, was unraveled, indicating an auto-inhibitory regulatory loop in gene transcription.

\section{Results}

\section{Subcellular localization of YB-1 deletion constructs}

Our starting hypothesis was that YB-1 protein fragments may be directed to different cellular compartments. Analyses of the subcellular distribution for full-length and truncated YB-1-GFP fusion proteins has been described in HeLa cells [4]. We first confirmed these results in our model system. Fusion proteins encompassing either the full-length YB-1 or various deletions, possessing a $\mathrm{C}$-terminal green fluorescent protein tag, were introduced into rat mesangial cells (RMC; Figure 1A). Some constructs encode for proteins with truncations of the C-terminal domain (denoted basic/acidic (B/A) or charged zipper domain); depicted in Figure 1A. To preserve comparability with previous results, we chose to introduce the same expression constructs used by Jurchott et al. [4]. Of note, the protein fragments span aa 1-317 of the YB-1 protein (accession number J03827)[9] and not of YBX1 (accession number NM_004559), that has a disparate length of 324 amino acids due to a later annotation of the database.

Cells were grown without cell cycle synchronization in medium containing 10\% FCS, as performed by Jurchott et al. [4]. For all immunofluorescence analyses, at least 100 transfected RMCs were assessed for their subcellular fluorescence distribution. Cells were grouped into five categories: (i.) exclusive nuclear (N), (ii.) exclusive cytoplasmic (C), (iii.) a pattern of uneven, predominantly nuclear (NC) or (iv.) predominantly cytoplasmic $(\mathrm{CN})$ or (v.) even nuclear/cytoplasmic (NC) distribution. Laser scanning microscopy detected the full-length YB-1 protein fused to eGFP exclusively in the cytoplasm (Figure 1B). Transfection of the control eGFP plasmid resulted in staining of both the nuclear and cytoplasmic compartments (Figure 1B, second panel). The $\mathrm{N}$ terminal YB-1 domains (aa 21-147) strictly localized to the cytoplasmic compartment, whereas the C-terminal domain aa 146-317 exhibited a nuclear localization (Figure 1B). Truncations within the YB-1 C-terminal domain, encoded by constructs P146-225 and P224-317, revealed that these are targeted to the nucleus, similarly to the fusion protein encompassing aa 172-225. The protein fragment P146-172 fused to eGFP was localized in both compartments. Of note, YB-1-eGFP fusion protein encoded by a longer construct covering aa 21-262 was exclusively detected in the cytoplasm, indicating that the nuclear localization signal(s) residing within aa 172-225 are not operative in a more extensive protein context that includes the N-terminal domains (Figure 1B). With the exception of the construct encoding for aa 21-262 all YB-1 deletion constructs behaved similarly, indicating that for the tested model systems there are no major differences with regard to YB-1 protein targeting.

\section{Fine-mapping of nuclear localization signals}

To narrow down the nuclear localization signals within the YB-1 protein, a computer-based search for known NLS was performed using the NUCDISC program (http://psort.nibb.ac.jp; [28]). The search revealed four hits, all residing within the C-terminal basic/acidic domain, that are (i.) aa 149-156, (ii.) 185-194, (iii.) 243249 and (iv.) 276-292. These motifs were tested in isolation by fusing them to a DsRed fluorescent tag at the N-terminus. The subcellular localization was determined following expression of the respective fluorescent proteins in RMCs (Figure 2A, B). To readily visualize the cellular compartments a plasmid encoding for cyan fluorescent protein (CFP) was co-introduced. CFP is predominantly detected within the nucleus at $552-627 \mathrm{~nm}$. CFP was chosen as the DsRed tag fluorescence spectrum overlaps with that of propidium iodine, thus precluding this method for nuclear counterstaining. 
The residues encompassing aa 149-156, aa 185-194 and aa 276-292 conferred an exclusive nuclear fluorescence pattern, whereas the aa 243-249 motif did not (Figure 2A, B). Since the motif at aa 149-156, denoted NLS-1, did not localize in the nucleus in the longer protein fragment encoded by P146-172 (Figure 1A, B), we therefore focused our attention on the motifs at residues aa 185-194 (NLS-2) and 276-292 (NLS-3) and evaluated their minimal composition for nuclear shuttling.
Mutational analyses of the nuclear localization signals NLS-2 and -3

The NLS-2 at residue aa 185-194 has been described by Bader and Vogt in chicken YB-1 [29]. As a general rule, NLS are comprised of at least seven residues with a high content of basic amino acids [18]. Therefore we generated five different constructs by introducing mutations to narrow down the minimal requirement(s) for nuclear localization and specifically address the question whether

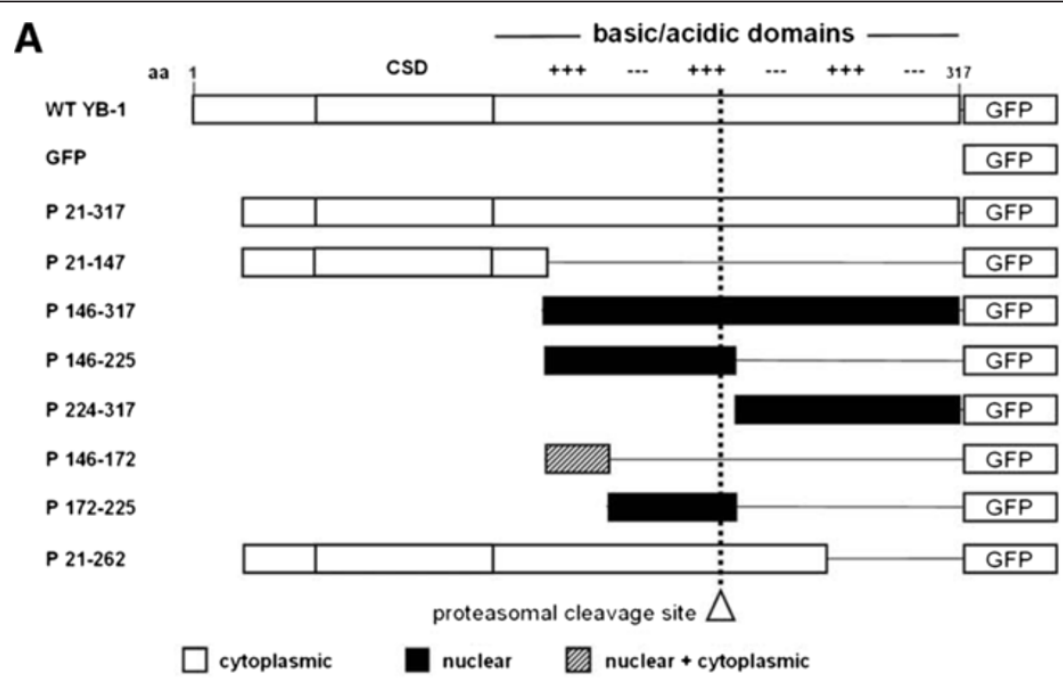

B

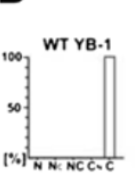

GFP
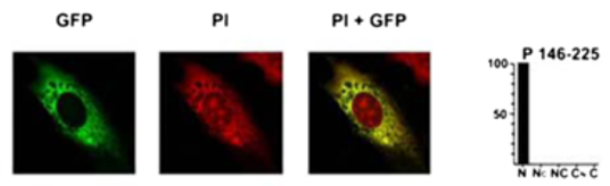

GFP

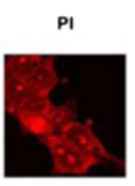

PI + GFP
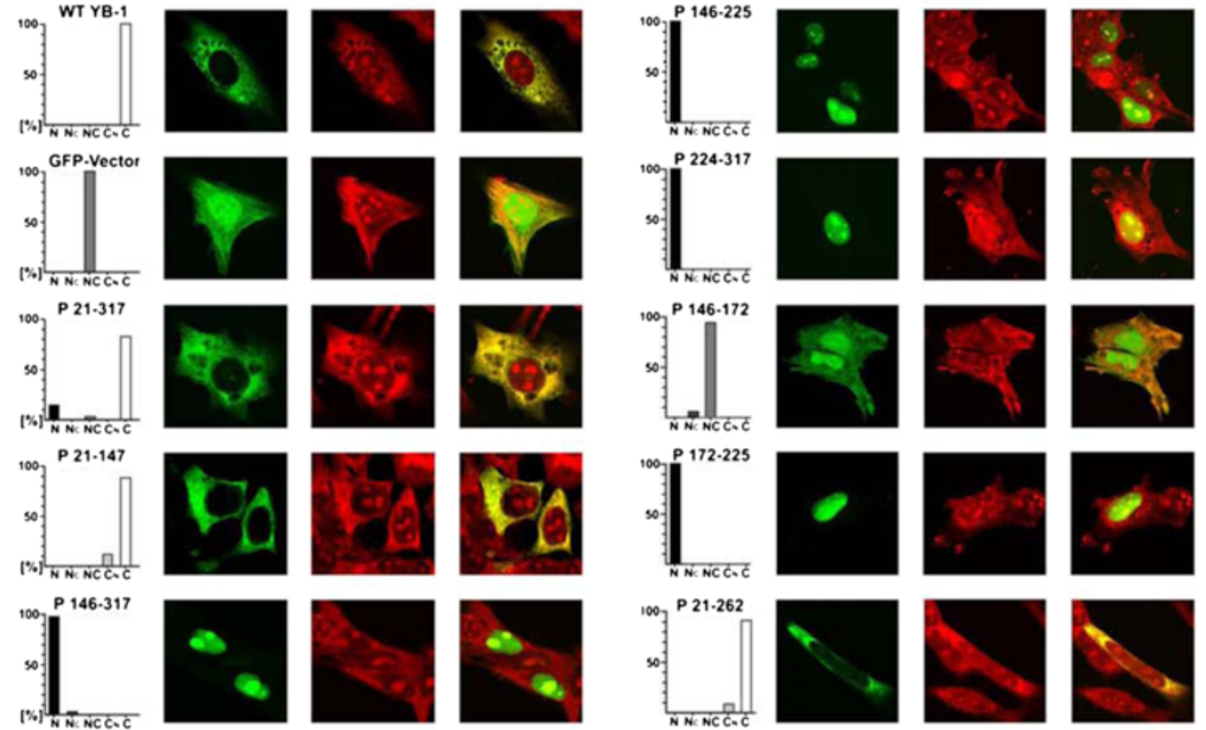

Figure 1 Localization of YB-1 and deletion constructs of YB-1. A. Schematic overview on GFP-tagged YB-1 (deletion) constructs. B. Localization of WT YB-1-GFP and YB-1 deletion constructs in proliferating RMC. Cells were transfected with expression vectors encoding for WT YB-1-GFP, YB-1 deletion constructs, or GFP. The subcellular localization was determined by confocal laser scanning microscopy, cell architecture was visualized by PI-staining. In the right column a merged overlay of PI staining and GFP fluorescence is shown. The percentages of cells with GFP-staining only in the nucleus $(\mathrm{N})$, predominantly in the nucleus and weak in the cytoplasm $\left(\mathrm{N}_{\mathrm{C}}\right)$, in both compartments equally $(\mathrm{NC})$, predominantly in the cytoplasm $\left(\mathrm{C}_{\mathrm{N}}\right)$, and only in the cytoplasm (C) are provided. 100 transfected cells were assessed for each plasmid. 


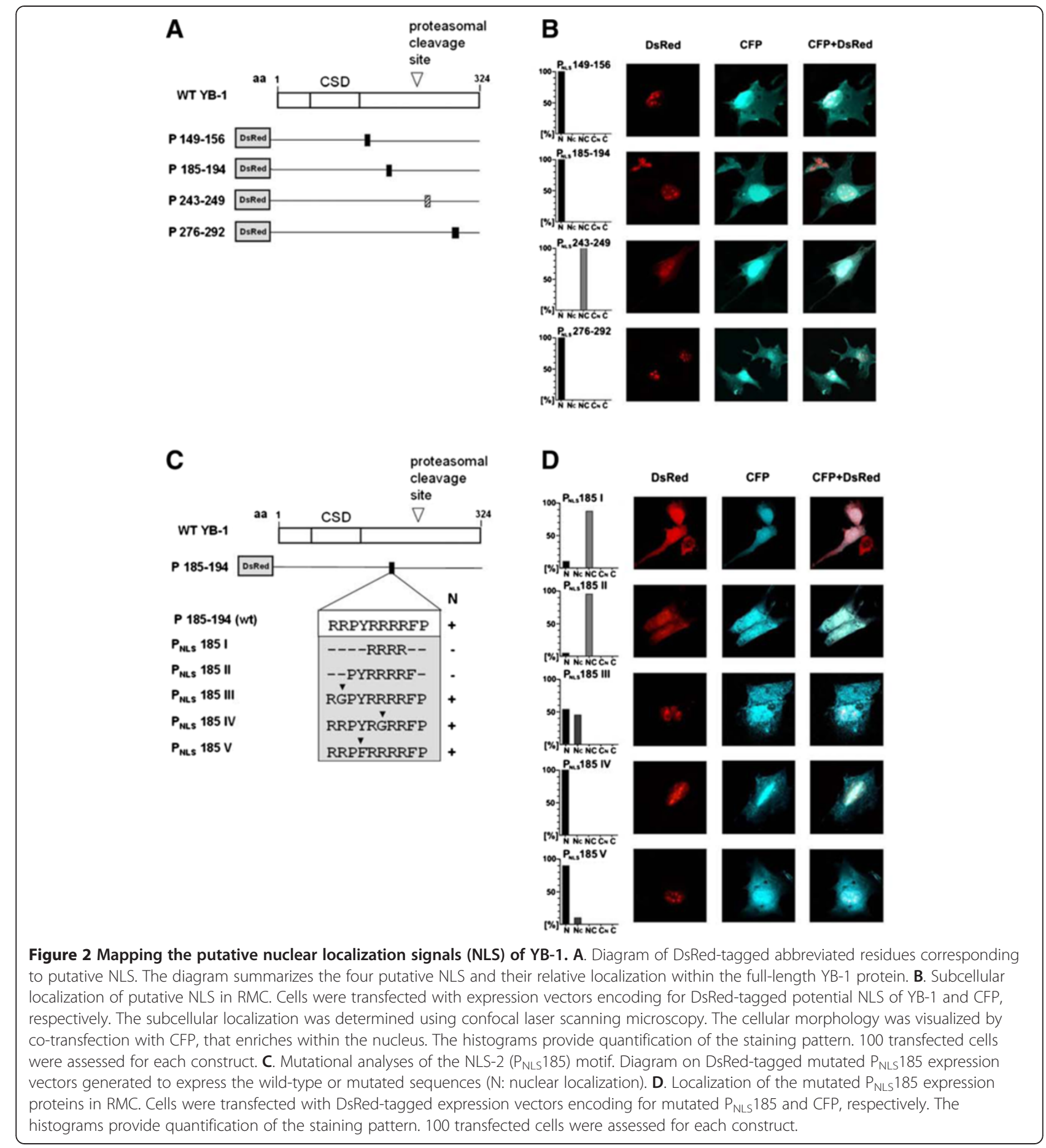

the tyrosine residue at aa 188 is required for functionality (Figure 2C). With constructs $\mathrm{P}_{\mathrm{NLS}} 185 \mathrm{I}$ and $\mathrm{P}_{\mathrm{NLS}} 185 \mathrm{II}$, an even cellular distribution of fusion proteins was observed (Figure 2D), indicating that the centrally located arginines alone are not sufficient for targeting. Exchange of either an arginine within the $\mathrm{N}$-terminal portion $\left(\mathrm{P}_{\mathrm{NLS}}\right.$ 185 III) or a central arginine ( $\mathrm{P}_{\mathrm{NLS}} 185 \mathrm{IV}$ ) with the neutral amino acid glycine had a minimal effect on nuclear localization, when compared to the wild-type NLS-2 motif. Replacing the tyrosine with phenylalanine at aa 188 $\left(\mathrm{P}_{\mathrm{NLS}} 185 \mathrm{~V}\right)$ also did not alter the nuclear localization, indicating that the minimal functional requirements of NLS-2 are independent of tyrosine 188 phosphorylation.

Inspection of the domains at aa 276-292 (NLS-3) revealed a bipartite composition of this motif. Both "arms" of the motif, PPQRRYRR and RRRRP, exhibit characteristics 
of nuclear localization signals (Figure 3A). These motifs are separated by an interspersed linker comprised of four amino acids. Testing of the partite motifs in isolation, encoded by plasmids $\mathrm{P}_{\mathrm{NLS}} 276 \mathrm{I}$ and $\mathrm{P}_{\mathrm{NLS}} 276 \mathrm{II}$, resulted in even cellular distribution of fluorescent protein. Deletion of the "linker" motif (NFNY; encoded by plasmid $\mathrm{P}_{\mathrm{NLS}} 276$ III) or extension of the "linker" by introduction of two additional glycine residues (encoded by plasmid $\mathrm{P}_{\mathrm{NLS}} 276 \mathrm{IV}$ ) did not impair functionality of nuclear targeting. Furthermore, we tested whether substitution of either tyrosine residue affects nuclear localization. Tyrosines were mutated to phenylalanine in two separate constructs $\left(\mathrm{P}_{\mathrm{NLS}} 276 \mathrm{~V}\right.$ and $\left.\mathrm{VI}\right)$, nevertheless, NLS-3 remained operative (Figure $3 \mathrm{~A}, \mathrm{~B}$ ).
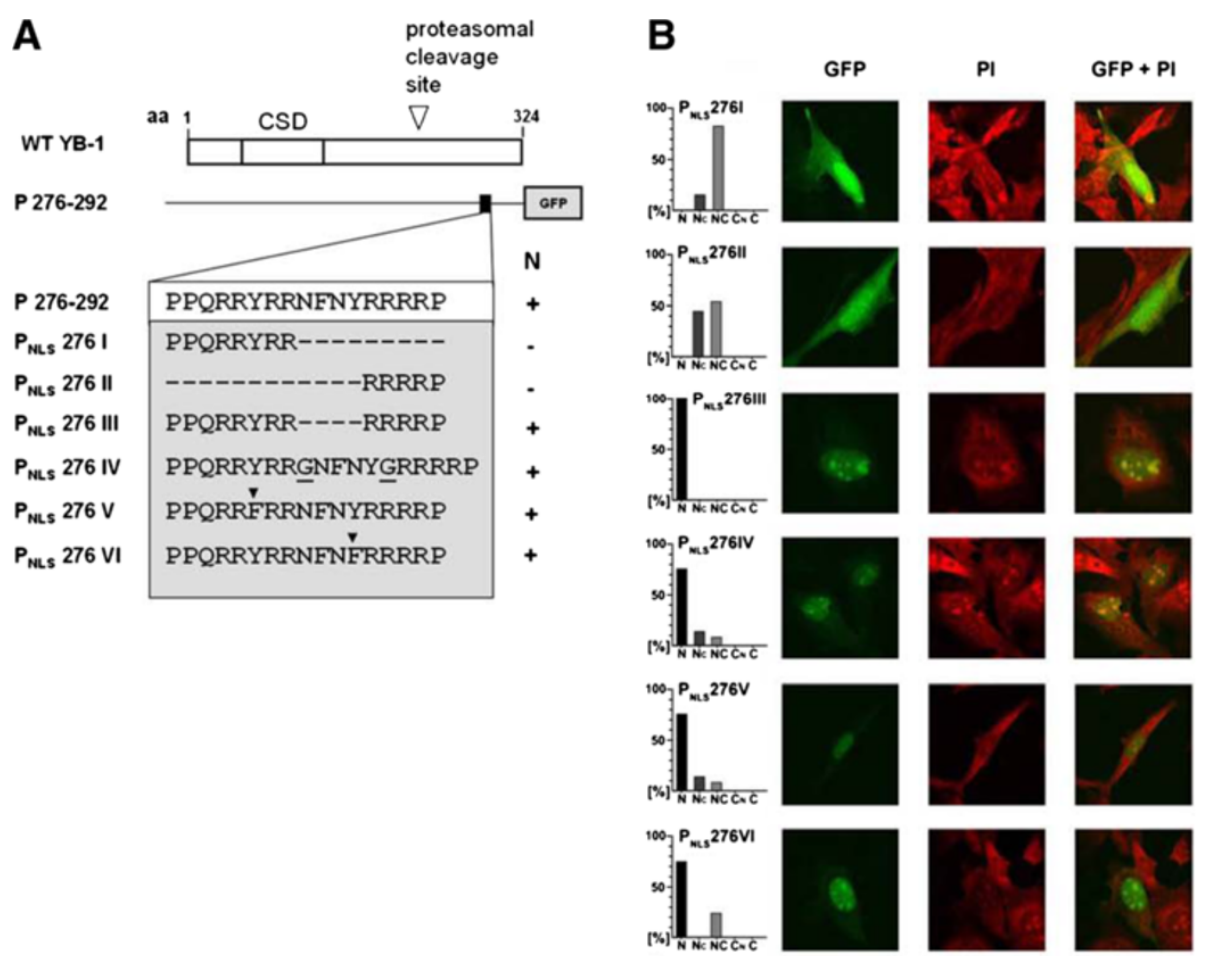

C NLS-3: H2N - PQR RYR RNF NYR RRR PC - CONH2 P-NLS-3: H2N - PQR RPYR RNF NYR RRR PC - CONH2

D

NLS-3

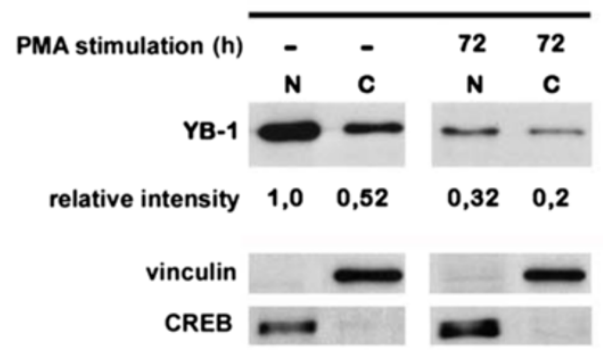

P-NLS-3

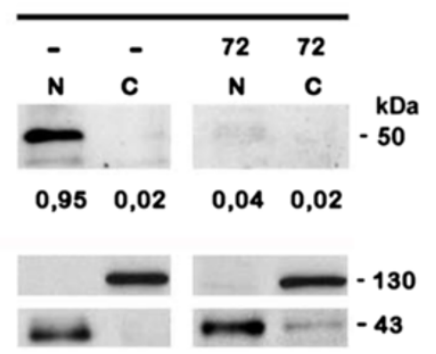

Figure 3 Mutational analyses of NLS-3 ( $\left.P_{\text {NLs }} 276\right)$ and immunoblotting of fractionated cell lysates. A. Diagram of DsRed-tagged mutated $\mathrm{P}_{\mathrm{NLS}} 276$ expression vectors generated to express wild-type or mutated amino acid sequences (N: nuclear localization). B. RMC were transfected with EGF-tagged expression vectors encoding for the mutated $\mathrm{P}_{\mathrm{NLS}} 276$ sequence. The subcellular localization was assessed by laser scanning microscopy. The histograms provide quantification of the staining pattern. 100 transfected cells were assessed for each construct. C. Amino acid sequences of the peptides used for immunization and affinity purification. D. Nuclear YB-1 protein is phosphorylated at NLS-3 in nondifferentiated monocytic, but not in differentiated THP-1 cells. Nuclear and cytoplasmic extracts were isolated from non-differentiated and differentiated THP-1 cells. Equal protein concentrations were loaded from each fraction. Immunoblotting was performed with the polyclonal antibodies generated against the unphosphorylated NLS-3 or tyrosine 281 phosphorylated sequence (P-NLS-3). Band intensities were quantified and normalized for nuclear CREB or cytoplasmic vinculin content. The cytoplasmic fraction has a 10x larger volume than the nuclear fraction. 


\section{Phosphorylation at tyrosine 281 of NLS-3 correlates with nuclear YB-1 shuttling}

The results obtained with the point-mutated NLS-3 motif (tyrosine exchanges) indicated that phenylalanine residues had no effect on the NLS-3 functionality in nonstimulated mesangial cells. Given that such results do not exclude phosphorylation of the tyrosine residues with subsequent alteration of functionality, we extended our analyses. As a model system we chose monocytic THP-1 cells, which express high levels of YB-1 and differentiate into adhering, amoeboid shaped macrophages following prolonged incubation with phorbol-12-myristate (PMA; 72 hours [30]). In accordance with previous work, a marked down-regulation of YB-1 expression was observed following PMA stimulation. It is known that PMA incubation affects intracellular signalling cascades and protein phosphorylation [30]. Western blot analyses were performed with two different polyclonal affinity-purified antibodies, prepared with unphosphorylated (NLS-3) and phosphorylated (P-NLS-3) peptides (Figure 3C). Phosphospecific antibody was affinity-purified following capture of the non-phospho-specific polyclonal immunoglobulins (flow-through following unphosphorylated peptide column incubation). This approach yielded highly specific immunoglobulin preparations suitable to determine the phosphorylation status, as confirmed in control blots with isolated peptides (not shown).

Fractionation of THP-1 cell lysates was performed and the phosphorylation status at NLS-3 assessed. Immunoblotting for cytoplasmic and nuclear marker proteins, vinculin and CREB, respectively, indicated successful fractionation. Undifferentiated THP-1 cells expressed YB-1 protein abundantly, with $\sim 70 \%$ of nonphosphorylated YB1 protein localizing to the nucleus (Figure 3D). Incubation of THP- 1 cells with PMA resulted in decreased YB-1 protein expression $(-80 \%)$ [30]. The YB-1 localization in differentiated THP-1 cells remained predominant nuclear (Figure 3D, left panel).

The same cell lysates were subjected to analyses with the phospho-specific antibody (Figure 3D, right panel). As a result, phosphorylation is only detected in the nuclear fraction of YB-1 in undifferentiated THP-1 cells. Cytoplasmic YB-1 was not detected, suggesting that cytoplasmic YB-1 is non-phosphorylated at NLS-3. In PMA-differentiated THP-1 cells, phosphorylation at tyrosine 281 was no longer detected. These results suggest that phosphorylation of tyrosine 281 in NLS-3 takes place and appears to correlate with nuclear protein shuttling (see also Additional file 1: Figure S1 and Additional file 2: Figure S2).

Two putative cytoplasmic retention (CRS)/nuclear export signals (NES) exist within the YB-1 N-terminal domains YB-1 protein residues aa 21-147 and aa 21-262 were fused to eGFP at the C-terminus. The resultant hybrid proteins yielded exclusive cytoplasmic fluorescence patterns, indicating the presence of operative CRS or NES within the domains spanning aa 21-147 (Figure 1B). Next, four deletion constructs were designed that encoded for partially overlapping domains within the N-terminus: aa $1-57$, aa $52-101$, aa $52-146$ and aa $69-$ 146. The results indicate that only aa 52-101/eGFP showed an exclusive cytoplasmic localization (summarized in Figure 4A, B).

A computer-aided search for nuclear export signals (NetNES 1.1 Server, http://www.cbs.dtu.dk; [31]) identified one potential motif at aa 100-109 (LRSVGDGETV). Similar to classical NES, this motif contains three of the four properly spaced hydrophobic residues and is rich in the amino acids serine, glutamate, and aspartate. This motif was tested in isolation, fused to eGFP at the C-terminus, yielding an even cellular distribution (Figure 4B). Of note, fluorescent protein encoded by P52-101 was visualized in a punctuated pattern and pronounced in vicinity to the nuclear membranes. An interaction of YB-1 with actin myofibrils has been demonstrated by co-immunoprecipitation studies [32]. By double immunofluorescence staining we were able to demonstrate co-localization of actin fibers with ectopically expressed fluorescent P52-101 protein (Figure 4C).

\section{The carboxy-terminal YB-1 cleavage fragment is targeted to the nucleus}

Sorokin et al. [33] described that YB-1 is endoproteolytically processed by the $20 \mathrm{~S}$ proteasome between amino acids $119 / 220$. The released N-terminal protein fragment was found to be transcriptionally active in the nucleus after thrombin stimulation of endothelial cells [34], whereas the carboxy-terminal fragment (CTF) has not been evaluated further. NLS-3 is situated within the 105 aa encompassing the CTF , suggesting that the CTF may also be targeted to the nucleus. The subcellular targeting of the CTF was analyzed by means of a construct encoding the CTF (aa 220-324) fused to eGFP at the C-terminus. This fluorescent protein was exclusively localized in the nucleus, with a pronounced speckled pattern (Figure 4D). We next asked whether over-expression of CTF affects the subcellular localization of full-length YB-1 protein, given that it may act as a decoy protein for the dimerization motif. The cellular content of untagged CTF was increased by means of expression vector pSG5(CTF). The co-introduced fluorescent full-length YB-1 protein was detected by laser scanning microscopy. In a reciprocal approach, full-length YB-1 protein levels were increased using the expression vector pSG5(YB-1) and the CTF fluorescent protein detected. Under both conditions the described compartmentalization of the proteins remained unaltered (Figure 4E). 


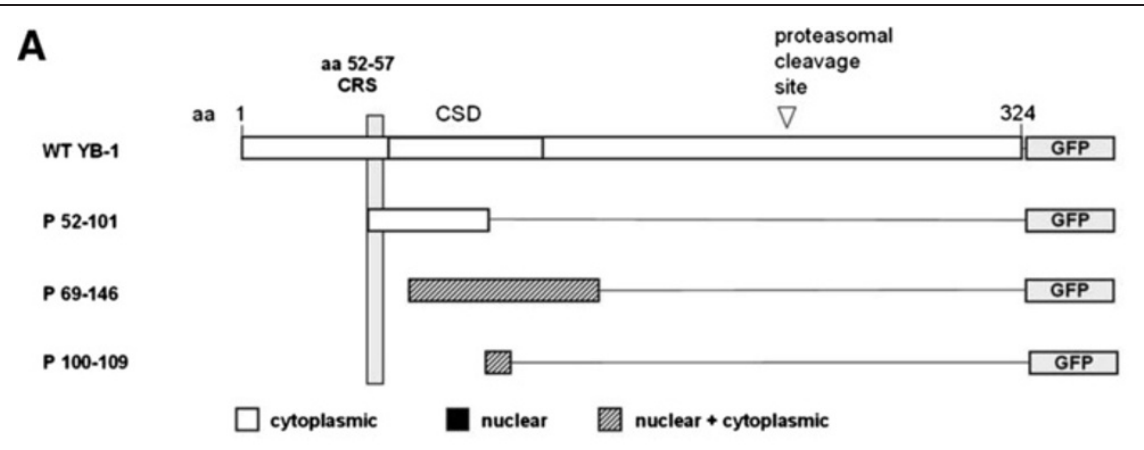

B

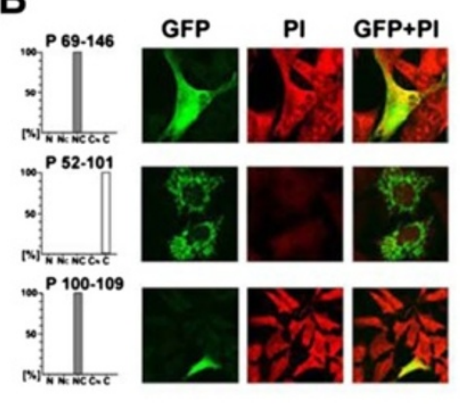

D

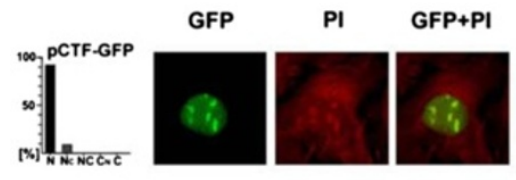

C

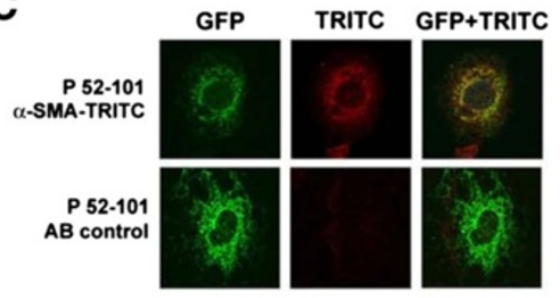

E

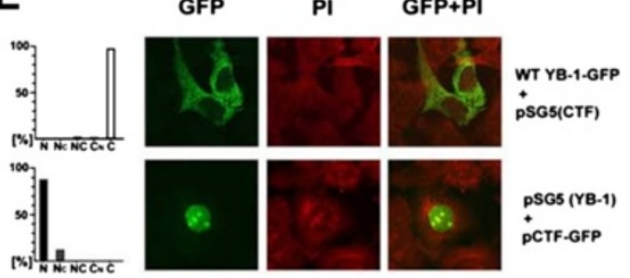

Figure 4 Mapping of the potential nuclear export signals (NES) of YB-1 and subcellular localization of the carboxy-terminal YB-1 protein fragment (CTF). A. Diagram on putative NES within the YB-1 protein. The composition of generated NES-constructs, denoted P1-57, P52-101, P52-146, and P69-146 with GFP-tags is provided. B. Localization of the tested constructs, denoted P69-146, P52-146, and P100-109, with GFP-tags in RMCs. The histograms provide quantification of the staining pattern. 100 transfected cells were assessed for each construct. C. Co-localization of P52-101 and a-smooth muscle actin in RMC. Cells were transfected with P52-101 (GFP-tagged) and after fixation, immunostained for a-smooth muscle actin (TRITC labelling). In the right column (GFP + TRITC) an overlay of TRITC and GFP staining is presented. D. Rat mesangial cells were transfected with an expression vector encoding for GFP-tagged CTF of YB-1 (pCTF). The subcellular localization was assessed using confocal laser scanning microscopy. The histogram provides quantification of the staining pattern. 100 transfected cells were counted. E. Localization of WT YB-1-GFP and CTF in co-transfected RMC. Cells were transfected with an expression vector encoding for WT YB-1-GFP and pSG-5(CTF), encoding for the untagged CTF. Furthermore, RMC were transfected with pCTF (GFP-tagged CTF) and the expression vector pSG5(YB-1) encoding for untagged YB-1. The subcellular localization was determined using confocal laser scanning microscopy. The histograms provide quantification of the staining pattern for 100 transfected cells.

\section{YB-1 proteolysis and subcellular targeting of domains following genotoxic stress}

The nuclear shuttling of YB-1 has been described under conditions of cellular stress. To address the question, whether proteolytic processing of $\mathrm{YB}-1$ and nuclear shuttling of the resulting protein fragments takes place cytotoxic stress experiments were designed. Doxorubicin, a common drug used to treat cancers of the bladder, breast, lung, or ovary, was added to the culture medium of MCF-7 breast cancer and rat mesangial cells in the absence and presence of the proteasome inhibitor MG-
132. The subcellular distribution of endogenous YB-1 protein was assessed using affinity-purified polyclonal antibodies targeting epitopes within the protein $\mathrm{N}$ - and C-terminus (Figure 5A). Immunofluorescence microscopy revealed that antibody preparations were specific for YB-1, (Additional file 3: Figure S3). In unchallenged cells, the C-terminal antibody detected YB-1 predominantly within the cytoplasm. A concentration-dependent shift to the nucleus was visualized following doxorubicin incubation (DOXO, 0.6 and $1.2 \mu \mathrm{g} / \mathrm{ml}$; Figure 5B). In order to assess whether cleavage of $\mathrm{YB}-1$ is a 

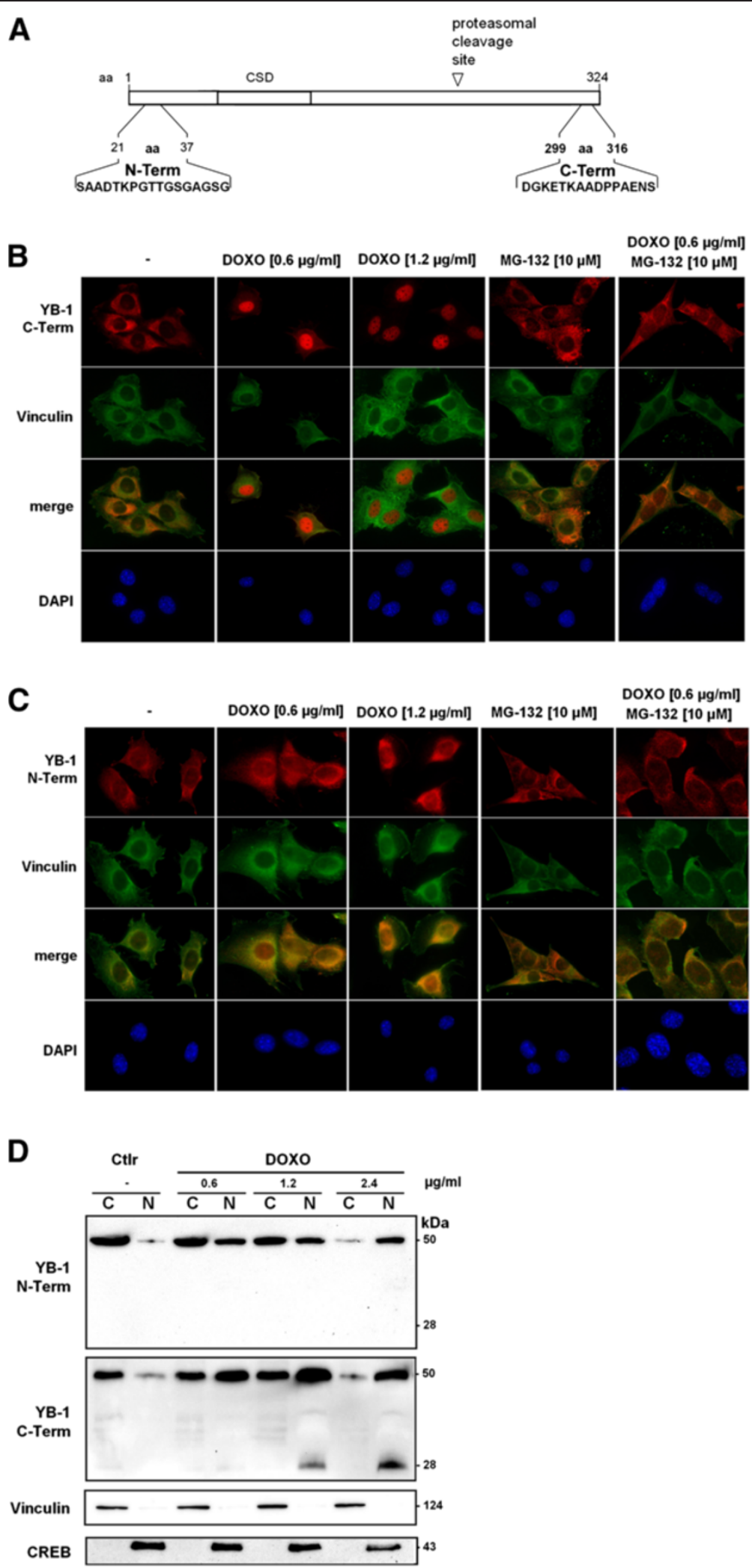

Figure 5 (See legend on next page.) 
(See figure on previous page.)

Figure 5 Subcellular localization of YB-1 protein fragments following genotoxic stress in the absence and presence of proteasome inhibitor. A. Schematic of YB-1 protein with its centrally localized cold shock domain. Polyclonal peptide-derived affinity-purified antibodies were generated against two epitopes localized either in the $\mathrm{N}$ - or C-terminus. B. Distribution of endogenous YB-1 protein was assessed by immunofluorescence microscopy in rat mesangial cells following immunodetection with the anti-YB-1 antiserum directed against the C-terminus (primary antibody). Murine anti-vinculin was used to visualize the cell structure. Fluorescently labelled secondary antibodies anti-rabbit IgG(Fab)Cy3 and anti-mouse lgG(Fab)-FITC were used for detection. Nuclei were visualized by DAPI staining. Rat mesangial cells were incubated for $16 \mathrm{~h}$ with doxorubicin at increasing concentrations $(0.6$ and $1.2 \mu \mathrm{g} / \mathrm{ml})$ in the absence or presence of proteasome inhibitor MG-132 (10 $\mu \mathrm{mol} / \mathrm{l})$. Images were taken at $\times 63$ magnification. $\mathbf{C}$. Distribution of endogenous YB-1 protein was assessed by immunofluorescence microscopy in rat mesangial cells according to the protocol outlined in $\mathbf{A}$ with polyclonal YB-1 antiserum directed against the $\mathrm{N}$-terminus ( $\mathrm{N}$-Term, primary antibody). D. Immunoblotting of fractionated cell lysates from rat mesangial cells exposed to doxorubicin at increasing concentrations (0.6, 1.2, and $2.4 \mu \mathrm{g} / \mathrm{ml}$ ). Cytoplasmic and nuclear proteins were separated and purity ascertained by detection of vinculin and CREB.

prerequisite for nuclear translocation, proteasome inhibitor MG-132 $(10 \mu \mathrm{M})$ was added to the cell culture medium and the cells challenged with doxorubicin. In cells preincubated with MG-132, most YB-1 protein remained cytoplasmic with only a minor fraction shuttling to the nucleus (Figure 5B). From this observation it may be concluded that proteasomal cleavage appears to be a prerequisite for nuclear translocation; although additional "activation" mechanisms may be operative. Next, the antibody specific for an epitope within the protein $\mathrm{N}$-terminus was utilized. In unchallenged cells, the N-terminal antibody detected YB-1 predominantly within the cytoplasm, similar to the results obtained with the C-terminal antibody. However, following genotoxic stress (Figure 5C), some YB-1 protein was still detected perinuclear. Preincubation with MG-132 yielded a predominantly cytoplasmic fluorescence pattern. The results suggest that cell stress-dependent protein cleavage is followed by nuclear shuttling of the protein C-terminal domain. To confirm that such a cleavage event occurs, cell fractionation was performed with rat mesangial cells exposed to increasing concentrations of doxorubicin (0.6, 1.2 , and $2.4 \mu \mathrm{g} / \mathrm{ml}$ ), followed by immunoblotting with the aforementioned antibodies (Figure 5D and Additional file 2: Figure S2). As a result, a concentration-dependent nuclear accumulation of full-length YB-1 was detected with both antibodies. In addition, a protein fragment with a relative molecular weight $\sim 28 \mathrm{kDa}$ was detected following doxorubicin exposure. This fragment is found exclusively in the nuclear fractions using the antibody recognizing the C-terminal epitope and is phosphorylated at NLS-3 (Additional file 2: Figure S2). Similar results were obtained using MCF-7 breast cancer cells (Additional file 4: Figure S4A/B). Again, a concentration-dependent shift of YB-1 to the nuclear compartment was visualized following doxorubicin incubation, a proteasome-dependent cleavage was evidenced by the same subcellular alterations as described for rat mesangial cells. Cell viability was assessed by trypan blue exclusion in control experiments with increasing concentrations of doxorubicin (Additional file 4: Figure S4C).

\section{The CTF influences the transcriptional activity of full- length YB-1}

In the following, we tested whether ectopically expressed CTF interferes with gene transcription orchestrated by overexpressed full-length YB-1, e.g. target gene MMP-2. Rat mesangial cells were transfected with the reporter construct pGL2MMP-2/RE-1 that harbours a YB-1 responsive enhancer element derived from the rat MMP-2 promoter $[35,36]$. The experimental set-up included cotransfections with empty expression vector pSG5, pSG5 (YB-1), pSG5(CTF), or the combination of the latter. As described before, full-length YB-1 overexpression enhanced the transcriptional activity of the MMP-2 promoter more than 100-fold under the chosen conditions ([11], Figure 6A). A similar induction of gene transcription was observed with ectopically expressed CTF, ranging between 100- and 200-fold even at low doses of plasmid DNA. When both expression plasmids, encoding full-length YB-1 or CTF, were co-transfected, the transcriptional activity was markedly repressed. Quantification revealed luciferase values at background levels (Figure 6A). The abrogation of full-length YB-1 transcriptional activity was determined with increasing concentrations of CTF expression plasmid. Thus, the CTF may functionally interfere with the trans-stimulatory effect of full-length YB-1 on target gene expression, whereas the CTF alone is capable of trans-activating gene transcription to a comparable extent as full-length YB-1 protein.

A trans-repressive effect of YB-1 on gene transcription, e.g. of the col $1 \alpha 1$ promoter, has also been described [37]. We next wished to evaluate whether the CTF alone may fulfill such a repressive effect. Rat mesangial cells were transfected with the well characterized promoter reporter construct pGL $\alpha 1-2.3$ [37]. Ectopic overexpression of fulllength YB-1 led to a suppression of transcriptional promoter activity by more than $90 \%$. Ectopic overexpression of CTF alone resulted in a similar reduction of promoter activity by $\sim 70 \%$ (Figure $6 \mathrm{~B}$ ). Co-expression of both, fulllength YB-1 protein and CTF, did not interfere with the repressive effect. 

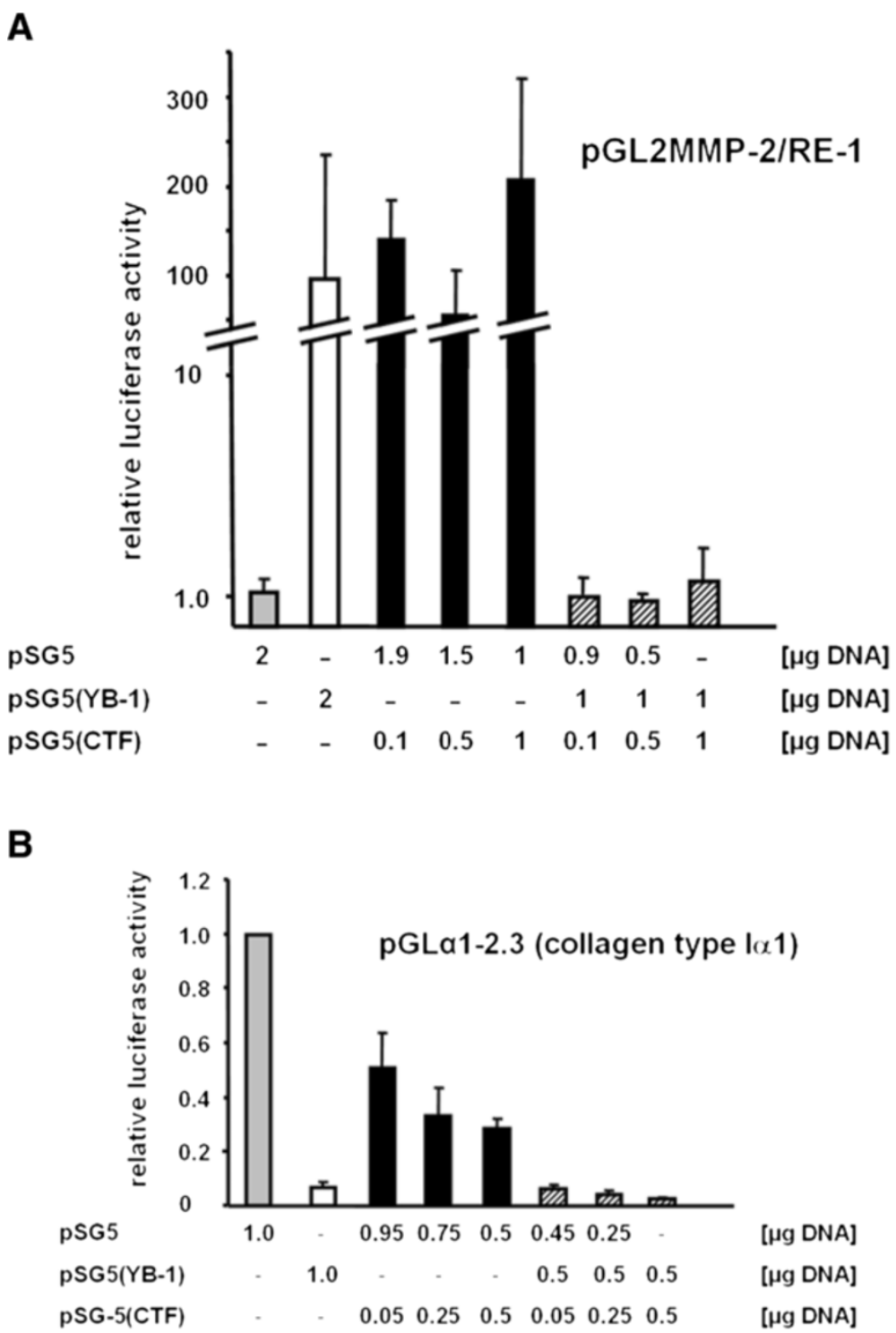

Figure 6 The carboxy-terminal YB-1 protein fragment (CTF) regulates transcriptional activity. A. Transcriptional activity of CTF on the MMP2 promotor construct PGL2MMP-2/RE-1. Rat mesangial cells were transfected with equal amounts of DNA (as indicated). After 48 hours cell lysates were prepared and luciferase assays were performed. All experiments were performed in triplicates and confirmed in three independent experiments. B. Transcriptional activity of the CTF on the Col1a1 promotor construct pGLa1-2.3. Rat mesangial cells were transfected with the indicated expression vectors and incubated for 48 hours. Luciferase assays were performed thereafter using cell lysates. All experiments were performed in triplicates and confirmed in three independent experiments.

\section{Discussion}

Our first quest was to determine the subcellular localization of full-length YB-1 protein as well as a series of truncated protein fragments (Figure 1). We confirmed in resting cells that full length YB-1 is primarily cytoplasmic. Construct encoding aa 21 to 262 yielded an equal fluorescent signal in the cytoplasm and nucleus, whereas it was exclusively cytoplasmic the previous study [4]. For the other constructs, no differences regarding subcellular targeting of YB-1 protein was detected in vitro.
Next we mapped the functional motifs and subdomains within the YB-1 protein that either confer nuclear shuttling/retention or cytoplasmic localization/ retention. Analogous to the report by Bader et al. [29] we detected functionality of the NLS at aa 185-194 (referred to here as NLS-2) in rat cells. In addition, two novel nuclear localization motifs located at aa 149-155 (NLS-1) and aa 276-292 (NLS-3) were mapped. Inspection of motif NLS-3 immediately suggested a bipartite composition. Mutational analyses confirmed that both parts are indeed required for functionality, at the same 
time alterations of the spatial organization of the two halves did not impair nuclear shuttling of a fluorescent fusion protein. Both NLS sequence motifs (NLS-2 and -3) contain tyrosine residues that are potential sites for phosphorylation, e.g. to regulate functionality of the NLS. To determine whether phosphorylation take place, we generated polyclonal peptide-based antibodies against the nonphosphorylated NLS-3 domain and the same antigen phosphorylated at tyrosine 281 . The results indicate that most of the YB-1 protein phosphorylated at tyrosine 281 within NLS-3 appears to be in the nucleus, whereas the cytoplasmic YB-1 protein appears unphosphorylated at this residue (Figure 3 and Additional file 2: Figure S2). These results indicate that phosphorylation at tyrosine 281 is accompanied by nearly exclusive nuclear localization of full-length YB-1, suggesting that the phosphorylated NLS-3 may act dominantly on the subcellular localization of Y-box protein. However, the data also show that this phosphorylation is not essential for nuclear localization. In addition, the data suggest that the localization of YB-1 may be highly regulated after cell stimulation. Stenina et al. [34] and Sorokin et al. [33] observed a nuclear localization of the truncated YB-1 protein containing $\mathrm{N}$-terminal portions of the protein in stimulated cells. For the amino-terminal domains of YB-1, a strict cytoplasmic localization was observed when the expressed YB-1 deletion/GFP-fusion proteins harbour aa 52-101. In an attempt to define nuclear export signalcontaining domains further constructs were designed that mapped to diverse regions of the protein $\mathrm{N}$-terminus (see Figure 6). However all of these "truncated" constructs lost their subcellular specification.

In summary, we could identify 3 different NLS, but no NES within the YB-1 protein. The existence of three different NLS within a protein underscores a careful regulation of its subcellular localization. The localization of phosphorylated NLS-3 within the nucleus of unstimulated cells raises many questions regarding its regulation. However, further scrutiny of the other NLSs shows that they also contain tyrosine residues, several for which the phosphorylation has already been reported (PhosphoSitePlus). Thus, the regulation of tyrosine phosphorylation and its role in the nuclear localization of YB-1 is an area that requires further study. Previous reports by Bader et al. have identified aa $137-183$ in participating as a multimerization domain of chicken YB-1 [29]. YB-1 multimerized in the presence and absence of DNA and RNA templates [38]. Therefore, it is possible that in the aggregates of multimerized YB-1, the region harboring the NLS-1 is hidden and thus no longer accessible to proteins involved in nuclear import.

Information on the subcellular localization of YB-1 protein in healthy tissue or in inflammatory diseases is scarce. In healthy kidney tissue, YB-1 was almost exclusively detected in the nucleus of glomerular and tubulointerstitial resident cells [39]. Following the induction of mesangioproliferative disease, a temporally and spatially coordinated up-regulation of YB-1 was detected in the cytoplasm of mesangial cells [39]. Such a tight regulation of the subcellular protein specification is one aspect that must be fulfilled to explain its involvement in pleiotropic functions, ranging from gene transcription to pre-mRNA splicing, mRNA translation, secretion, and receptor interaction $[40,41]$.

In the studies by Sorokin et al. [33] the focus was placed on the N-terminal fragment. Somewhat surprisingly, we did not detect this fragment with our $\mathrm{N}$-terminal antibody after stress induction (Figure 5D), however we clearly detect the CTF, which may suggest a differential processing of YB-1 that is signal-dependent. Our inability to detect the N-terminal fragment of YB-1 suggests that it is either post-translational modified, thus masking the epitope, or degraded. While there are no reported phosphorylation sites within the epitope (aa 10-22), there are multiple lysine residues that are sites of ubiquitinylation (PhosphoSitePlus [42]). Additionally, YB-1 associates via its N-terminus with FBX33, a component of an SCF E3-ubiquitin ligase; an interaction that targets YB-1 for proteasomal degradation [43]. However, the issue of whether proteolytic processing of YB-1 occurs is still disputed [44,45].

We extended the functional analyses by creating an expression plasmid encoding for the CTF only. The effect of ectopically expressed CTF on gene transcription from enhancer and silencer elements, respectively, of YB-1 target genes MMP-2 and collagen type I $[11,37]$ were analyzed. In rat mesangial cells ectopic overexpression of the CTF resulted in increased transcriptional activity of the MMP2 response element-1, as was shown before for full-length YB-1 (Figure 6). Notably, co-expression of CTF and fulllength YB-1 resulted in a loss of transcriptional transactivation of the same element. Thus, the carboxyterminal YB-1 protein fragment aa 220-324, lacking the described DNA- or RNA-binding cold shock domain [46], acts dominant-negatively on full-length YB-1-dependent gene transcription. The CTF, which is composed of basic/ acidic repeats, is generally thought to mediate proteinprotein interactions [1]. However, the B/A motifs from the C-terminus of Y-box proteins have also been shown to have nucleic acid-binding activity [46,47]. Thus, a DNA binding mechanism would be an obvious explanation, however other possibilities could be envisioned (e.g. a decoy function that influences protein-protein interactions to promote or inhibit complex formation or YB-1 oligomerization). Further investigations will be required to elucidate this mechanism of action.

A hypothetical model for the functionality of the CTF was set up, emphasizing the need for cooperative protein 
interactions to direct gene transcription and also the novel regulatory ramifications with the CTF acting on gene transcription. In normal, unstressed cells fulllength YB-1 is primarily cytoplasmatic (Figure 7). In the case of genotoxic stress, a subset of the full-length YB-1 protein is cleaved by the $20 \mathrm{~S}$ proteasome. Both the fulllength protein and the cleavage products localize to the nucleus, resulting in a loss of transcriptional activity at the MMP-2 promoter. This effect may be dependent on the half lives of the distinct protein fragments (Figure 7). It will be of interest to see whether other functions of YB-1, such as mRNA binding and translation processes, are also regulated by the CTF. Of note there was a trans-repressive effect of the CTF on the collagen type I promoter element, that was not subjected to interference with wild-type protein activities. Thus it appears that the activating and repressive activities of YB-1 on gene transcription may involve mechanisms that reflect a requirement for different levels of YB-1 oligomerization and/or perhaps different binding partners.

\section{Conclusions}

The full spectrum of signals that induce either the phosphorylation and/or proteolytic processing of YB-1 still

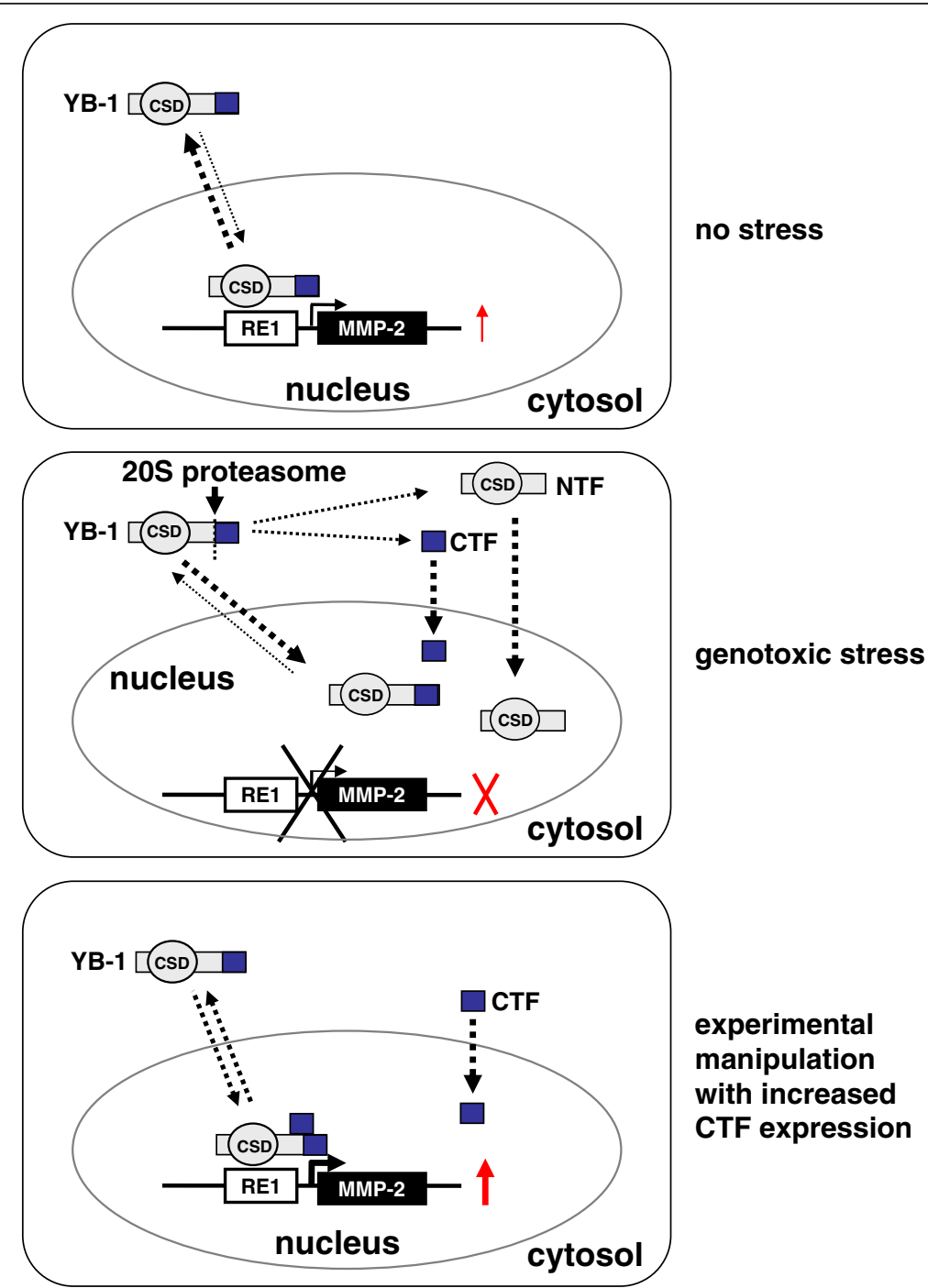

Figure 7 Model of the functional activities for the C-terminal fragment (CTF) of YB-1. In non-stressed cells full-length YB-1 protein is predominantly cytoplasmic and may shuttle between the nucleus and cytoplasm. In the nucleus, full-length YB-1 binds to the RE-1 element within the MMP-2 promotor and trans-activates gene transcription. Following genotoxic stress, full-length YB-1 is predominantly localized in the nuclear compartment. In addition, cleavage of full-length YB-1 protein by the 205 proteasome takes place; whether this occurs in the cytoplasm or nucleus has not been investigated. The cleaved C-terminal fragment (CTF) also resides within the nuclear compartment. Co-localization of full-length YB-1 and CTF in the nuclear compartment results in loss of transcriptional trans-regulation of the MMP-2 promoter. The MMP-2 promoter is transcriptionally activated by ectopically expressing CTF, that readily shuttles to the nucleus. 
remains to be determined. It is interesting to speculate to what extent these processes may contribute to pathology, particularly as enhanced levels of nuclear YB-1 are often associated with a poor prognosis in cancer $[45,48,49]$. Proteasome inhibitors have been introduced into therapeutical regimens of hematological disorders like multipe myeloma. Of note, experimental evidence indicates that proteasomal inhibitors like bortezomib may exert profound antiinflammatory activities in kidney diseases, like lupus nephritis [50] and necrotizing glomerulonephritis [51]. Future studies will address the important question of whether the prevention of YB-1 cleavage via proteasomal inhibition contributes to these anti-inflammatory activities.

\section{Methods}

\section{Cell culture}

Rat mesangial cells were established as previously described [52,53]. Human monocytic THP-1 as well as human breast adenocarcinoma MCF-7 (Michigan Cancer Foundation-7) cells were obtained from the ATCC. RMCs and THP-1 cells were grown in RPMI 1640 medium supplemented with $10 \%$ fetal calf serum, $2 \mathrm{mM} \mathrm{L}$-glutamin, $100 \mu \mathrm{g} / \mathrm{ml}$ of streptomycin and 100 $\mathrm{U} / \mathrm{ml}$ penicillin at $37^{\circ} \mathrm{C}$ in humidified $5 \% \mathrm{CO}_{2}$. MCF-7 cells were grown in DMEM medium supplemented as described above.

\section{Plasmids}

Plasmids encoding for the WT YB-1 fusion protein and the GFP-tagged deletion constructs were obtained from K. Jürchott (Max-Delbrück Center, Berlin, Germany). For characterization of the NLS and NES, DNA fragments of the YB-1 sequence (gene AC J03827) were cloned into the vector pDsRed2-C1 or pEGFP-N1 (BD Biosciences Clontech, Heidelberg, Germany). The fusion proteins were tagged with DsRed2 at the $\mathrm{N}$-terminus or EGFP at the C-terminus, respectively. Inserts were generated by PCR using the full-length WT YB-1 vector as template and primers as described in Additional file 5: Table S1, and digested with EcoRI/BamHI or BglII/ EcoRI. For the generation of the small deletion constructs and mutational analyses annealed oligonucleotides (Invitrogen, Karlsruhe, Germany), as described in Additional file 6: Tables S2 and Additional file 7: Table $\mathrm{S} 3$, were ligated into pDsRed2-C1 or pEGFP-N1 vectors, respectively. All nucleotide sequences were verified by automated sequencing.

\section{Transient transfection and laser scanning microscopy}

RMC were grown to $60-80 \%$ confluency on coverslips in 6-well culture plates and transiently transfected with Fugene $^{\oplus} 6$ according to the manufacturers instructions (Roche, Basel, Switzerland). Briefly, $2 \mu \mathrm{g}$ plasmid DNA and $6 \mu \mathrm{l}$ Fugene solution were gently mixed in $80 \mu \mathrm{l}$ serum-free RPMI 1640 medium and incubated for 1 hour. RMC transfected with pDSRed 2 derived vectors $(1 \mu \mathrm{g})$ were cotransfected with $1 \mu \mathrm{g}$ of pCFP vector (BD Biosciences Clontech, Heidelberg, Germany). The transfected cells were washed twice with PBS and then fixed with $4 \%$ paraformaldehyde/PBS for 30 minutes. In transfection studies with GFP-tagged vectors, nuclear staining was achieved by adding propidium iodine in a concentration of $5 \mu \mathrm{g} / \mathrm{ml}$ for $10 \mathrm{~min}$ at room temperature. Cells were mounted with immuno-mount (Shandon, Pittsburgh, USA) and analyzed by laser scanning microscopy (Axiovert $100 \mathrm{M}$ confocal laser scanning microscope, Carl Zeiss, Oberkochen, Germany), using a dual parameter setup and dual wave-length excitation at $488 \mathrm{~nm}$ and $543 \mathrm{~nm}$ for detection of GFP/PI fluorescence or $458 \mathrm{~nm}$ and $543 \mathrm{~nm}$ for DsRed/CFP fluorescence. All transfection experiments were performed at least three times.

\section{Luciferase assays}

For luciferase activity measurements, RMC were transfected with pSG5, pSG5(YB-1), and/or pSG5(CTF) expression vectors together with the promoter constructs pGL2MMP-2/RE-1 in 6 or 12 well plates and incubated for 48 hours. After 48 hours, cells were harvested in $100 \mu \mathrm{l}$ reporter lysis buffer and luciferase assays were performed with $20 \mu \mathrm{l}$ of lysates using the Luciferase assay system (Promega, Madison, WI, USA). All assays were performed in triplicate.

\section{THP-1 differentiation}

THP-1 cells were differentiated into adherent macrophagelike cells by incubation with phorbol-12-myristate for 72 hours (PMA, 100 nM; Sigma-Aldrich, Seelze, Germany). Nuclear and cytoplasmic cell extracts were prepared as previously described [11]. Protein concentrations were determined sing the Bio-Rad protein assay and bovine serum albumin as a standard. Proteins were subjected to SDS-PAGE, transferred to nitrocellulose, and detected with suitable polyclonal antibodies to NLS-3, or P-NLS-3 (Eurogentech, Köln, Germany), vinculin, or CREB. Protein bands were visualized using ECL (Amersham Biosciences, Piscataway, NJ, USA). Band intensities were quantified using the Scion Image software. The YB-1 protein content in cells without PMA-treatment was set to one.

\section{Antibodies}

Two peptide-derived rabbit polyclonal anti-YB-1 sera, recognizing epitopes aa 21-37 and 306-321 of YB-1, were generated as previously described [39,40,54,55]. Sera were used at a dilution of 1:100 for immunofluorescence (IF) and 1:1000 for Western blotting (WB). A monoclonal antibody against Vinculin was purchased 
from (Fitzgerald Industries, Acton, Massachusetts, USA) and used at 1:100 for IF and 1:1000 for WB. A monoclonal antibody against CREB was purchased from (Cell Signaling, Danvers, MA, USA) and used at 1:1000 for WB. Horse radish peroxidise-linked anti-rabbit and -mouse antibodies (SouthernBiotech, Birmingham, Alabama, USA) for WB (dilutions 1:5000 to 1:10,000). Cy3-labeled anti-rabbit antibody (Sigma-Aldrich, Seelze, Germany) and FITClabeled anti-mouse antibody (Dako Deutschland $\mathrm{GmbH}$, Hamburg, Germany) were used for IF.

\section{Cell viability}

A trypan blue (Sigma-Aldrich, Seelze, Germany) exclusion assay was performed as described [52].

\section{Cytoplasm and nuclear fractionation}

RMC and MCF-7 cells were washed twice with PBS and lysed in Nuclear Extraction Buffer A (10 mM Hepes, $10 \mathrm{mM} \mathrm{KCl}, 0.1 \mathrm{mM}$ EDTA) containing complete protease inhibitor cocktail (Roche, Basel, Switzerland) at $4^{\circ} \mathrm{C}$ for $15 \mathrm{~min}$ and centrifuged at $15,000 \times \mathrm{g}$ for $3 \mathrm{~min}$ at $4^{\circ} \mathrm{C}$. Supernatants containing cytoplasmic proteins were collected. Pellets resuspended in Nuclear Extraction Buffer $\mathrm{A}$ and centrifuged at $15,000 \times \mathrm{g}$ for $3 \mathrm{~min}$ at $4^{\circ} \mathrm{C}$. Supernatants were decanted. Steps were repeated two more times. Pellets resuspended in Nuclear Extraction Buffer B (20 mM Hepes, 0.4 M NaCl, 1 mM EDTA, 10\% Glycerol) containing complete protease inhibitor cocktail (Roche) at $4^{\circ} \mathrm{C}$ for $20 \mathrm{~min}$ and centrifuged at 25,000 $\times \mathrm{g}$ for $5 \mathrm{~min}$ at $4^{\circ} \mathrm{C}$. Supernatants containing nuclear proteins were collected and protein concentrations of the different fractions determined by BioRad protein assay (BioRad, Munich, Germany) with BSA as a standard.

\section{Western blotting}

Denatured protein samples were separated by electrophoresis in 10\% SDS-PAGE, transferred onto nitrocellulose membranes, blocked with 5\% milk in PBS-tween (PBST), washed with PBST, and incubated with primary antibodies (described above) diluted in PBST overnight at $4^{\circ} \mathrm{C}$. Primary antibodies were detected using HRPconjugated secondary antibodies (described above) diluted in PBST for two hours at room temperature.

\section{Immunofluorescence microscopy}

MCF-7 and RMC cells were grown on glass coverslips. Twenty-four hours later, the cells were treated with different concentration of doxorubicin for fourteen hours. After incubation with doxorubicin, the cells were washed twice with PBS to remove non-adherent cells and fixed with $4 \%$ paraformaldehyde in PBS. Two different peptide-derived rabbit polyclonal anti-YB-1 antibodies and mouse anti-viniculin were used (1:100). Secondary antibodies Cy3-labeled anti-rabbit (Sigma-
Aldrich, Seelze, Germany), and FITC-labeled antimouse (Dako Deutschland GmbH, Hamburg, Deutschland) were diluted 1:300 . Nuclei were counterstained with DAPI (Invitrogen, Karlsruhe, Germany). Cells were mounted with fluorescence mounting medium (Dako Deutschland $\mathrm{GmbH}$, Hamburg, Germany) and analyzed using a fluorescence microscope (DM6000 B; Leica Microsystems GmbH, Darmstadt, Germany) equipped with a CCD Camera (DFC340 FX; Leica Microsystems GmbH, Darmstadt, Germany) and a 63/1.4 objective. Separate images were taken and later merged using Image ${ }^{\mathrm{TM}}$ software.

\section{Additional files}

Additional file 1: Figure S1. Antibody specificity testing with and without calf intestinal alkaline phosphatase treatment. Rat mesangial cells were left untreated (-) or treated (+) with the protein tyrosine phosphatase inhibitor pervanadate (PV) to maximize phosphorylation. Cell lysates were loaded in duplicate, separated by SDS-PAGE, and transferred onto membranes. The membrane was cut and blocked. In addition, one membrane was incubated in alkaline phosphate buffer with $1 \mathrm{U}$ calf intestinal alkaline phosphatase (CIP)/ $\mu \mathrm{g}$ protein for 60 minutes (+CIP). The membranes were the incubated with primary antibody as indicated and visualized using ECL detection. As seen, CIP treatment completely ablates the signal detected using the pNLS3 antibody demonstrating its phospho-specificity. The pan-phosphotyrosine antibody [4G10] shows that not all tyrosine phosphorylation has been removed. The YB-1 and $\beta$-tubulin signals are comparable. The position of the protein standards and the relative molecular weight (MW) in kiloDaltons $(\mathrm{kDa})$ are indicated.

Additional file 2: Figure S2. Subcellular localization of YB-1 protein fragments following genotoxic stress. Immunoblotting of fractionated cell lysates from rat mesangial cells exposed to doxorubicin for $14 \mathrm{~h}$ at increasing concentrations $(0.6,1.2$, and $2.4 \mu \mathrm{g} / \mathrm{ml})$. Cytoplasmic and nuclear proteins were separated and purity ascertained by detection of vinculin and CREB. Additionally, blotting with the pNLS3 antibody shows that the phosphorylated C-terminal fragment (p28) is found exclusively in the nuclear fraction.

Additional file 3: Figure S3. Antibody specificity testing with preincubation of immunization peptides in MCF-7 cells. Distribution of endogenous YB-1 protein was assessed by immunofluorescence microscopy in MCF-7 cells with a peptide-derived affinity purified polyclonal YB-1 antiserum directed against the N-terminus (primary antibody). Upper left panel: untreated N-terminal antibody. Upper middle panel: antibody mixed with $0.1 \mu \mathrm{g} / \mathrm{ml}$ of immunizing peptide (YB-1 amino acids 21 to 37: SAADTKPGTTGSGAGSG). Upper right panel: antibody mixed with with $1 \mu \mathrm{g} / \mathrm{ml}$ of immunizing peptide. Middle panels: Murine anti-vinculin antibody was utilized to visualize the cell structure. Lower panels: Nuclei were visualized with DAPI. Images were taken at $\times 63$ magnification.

Additional file 4: Figure S4. Subcellular localization of YB-1 protein fragments following genotoxic stress in the absence and presence of proteasomal inhibitor in MCF-7 breast cancer cells. 1 2. A. Distribution of endogenous YB-1 protein was assessed by immunofluorescence microscopy in MCF-7 cells following immunodetection with the anti-YB-1 antiserum directed against the C-terminus (primary antibody). Murine anti-vinculin antibody was utilized to visualize cell structures.

Fluorescence labelled secondary antibodies consisted of anti-rabbit lgG (Fab)-Cy3 and anti-mouse lgG(Fab)-FITC. Nuclei were visualized by DAPI staining. MCF-7 cells were incubated for $16 \mathrm{~h}$ with doxorubicin at increasing concentrations $(0.6$ and $1.2 \mu \mathrm{g} / \mathrm{ml})$ in the absence or presence of proteasome inhibitor MG-132 (7.5 and $10 \mu \mathrm{mol} / \mathrm{l})$. Images were taken at $\times 63$ magnification. B. Distribution of endogenous YB-1 protein was assessed by immunofluorescence microscopy in MCF-7 cells according to the protocol outlined in A with polyclonal YB-1 antiserum directed 
against the N-terminus (N-Term, primary antibody). C. Cytotoxicity assay with increasing concentrations of doxorubicin. Rat mesangial cells $(1 \times 106 /$ well) were seeded in 24-well plates in RPMI medium (with $10 \%$ FCS) followed by treatment with the indicated concentrations of doxorubicin for $16 \mathrm{~h}$. Cell viability was then measured using Trypan blue reagent.

Additional file 5: Table S1. Primers used for the cloning of deletion constructs.

Additional file 6: Table S2. Primers used for the cloning of small deletion constructs.

Additional file 7: Table S3. Primers used for the cloning of mutational analyses constructs.

\section{Abbreviations}

CFP: Cyan fluorescent protein; CRS: Cytoplasmic retention signal; CSD: Cold shock domain; CSP: Cold shock protein; CTF: Carboxy-terminal fragment; DMEM: Dulbecco's Modified Eagles Medium; DOXO: Doxorubicin; eGFP: Enhanced green fluorescent protein; FITC: Fluorescein isothiocyanate; GM-CSF: Granulocyte macrophage-colony stimulating factor; IF: Immune fluorescence; IFNY: Interferon gamma; IL-2: Interleukin 2; MCF-7: Michigan Cancer Foundation-7; MDR-1: Multidrug resistance 1; MMP-2: Matrix metalloproteinase 2; mRNPs: Messenger ribonucleoprotein particles; MRP2: Multidrug resistance protein 2; NES: Nuclear export signals; NLS: Nuclear localization signals; PBS: Phosphate buffered saline; PBST: Phosphate buffered saline tween; RMC: Rat mesangial cells; SDS-PAGE: Sodium dodecylsulfate-polyacrylamide gel electrophoresis; WB: Western blotting; YB-1: Y-box protein-1.

\section{Competing interests}

The authors declare no competing financial interests.

\section{Authors' contributions}

C.R.C.VR., F.G.S. designed and performed experiments, analyzed and interpreted results, and wrote the manuscript; S.B., V.A.K., S.M., S.D., U.R. performed experiments and analyzed data; H-D.R. designed and contributed vital reagents; S.E.D., S.D., H.W. designed experiments, interpreted results, and wrote the manuscript; T.F. designed contributed vital reagents, analyzed and interpreted results; J.A.L. designed and performed experiments, analyzed and interpreted results, and wrote the manuscript; and P.R.M. directed the study, designed experiments, supervised the work, interpreted results, and edited the manuscript. All authors read and approved the final manuscript.

\section{Acknowledgements}

This study was supported by grants from the Deutsche Forschungsgemeinschaft (DFG), Sonderforschungsbereich 854 (project 01) and Me1365/7-1 to PRM and RO4036/1-1 to CRCVR.

\section{Author details}

'Department of Nephrology and Clinical Immunology, RWTH Aachen University, Aachen, Germany. ${ }^{2}$ Department of Nephrology and Hypertension, Diabetes and Endocrinology, Otto-von-Guericke University Magdeburg, Leipziger Str 44, 39120 Magdeburg, Germany. ${ }^{3}$ Breast Cancer Research, Center of Advanced European Studies and Research, Caesar, Bonn, Germany. ${ }^{4}$ Department of Nephrology, University of Thessaly, Larissa, Greece. ${ }^{5}$ Laboratory for Oncogenomic Research, Departments of Pediatrics and Experimental Medicine, Child and Family Research Institute, University of British Columbia, Vancouver, British Columbia, Canada. ${ }^{6}$ Molecular Hepatology, Department of Medicine II, University of Heidelberg, Mannheim, Germany. ${ }^{7}$ Department of Hematology and Oncology, Otto-von-Guericke University Magdeburg, Magdeburg, Germany.

Received: 13 February 2013 Accepted: 12 August 2013 Published: 27 August 2013

\section{References}

1. Wolffe AP: Structural and functional properties of the evolutionarily ancient Y-box family of nucleic acid binding proteins. Bioessays 1994, $16: 245-251$
2. Jones $P G$, VanBogelen RA, Neidhardt FC: Induction of proteins in response to low temperature in Escherichia coli. J Bacteriol 1987, 169:2092-2095.

3. En-Nia A, Yilmaz E, Klinge U, Lovett DH, Stefanidis I, Mertens PR: Transcription factor YB-1 mediates DNA polymerase alpha gene expression. J Biol Chem 2005, 280:7702-7711.

4. Jurchott K, Bergmann S, Stein U, Walther W, Janz M, Manni I, Piaggio G, Fietze E, Dietel M, Royer HD: YB-1 as a cell cycle-regulated transcription factor facilitating cyclin A and cyclin B1 gene expression. J Biol Chem 2003, 278:27988-27996.

5. Homer C, Knight DA, Hananeia L, Sheard P, Risk J, Lasham A, Royds JA, Braithwaite AW: Y-box factor YB1 controls p53 apoptotic function. Oncogene 2005, 24:8314-8325.

6. Higashi K, Inagaki Y, Suzuki N, Mitsui S, Mauviel A, Kaneko H, Nakatsuka I: Y-box-binding protein YB-1 mediates transcriptional repression of human alpha 2(I) collagen gene expression by interferon-gamma. J Biol Chem 2003, 278:5156-5162.

7. Chen CY, Gherzi R, Andersen JS, Gaietta G, Jurchott K, Royer HD, Mann M, Karin M: Nucleolin and YB-1 are required for JNK-mediated interleukin-2 mRNA stabilization during T-cell activation. Genes Dev 2000, 14:1236-1248.

8. Diamond P, Shannon MF, Vadas MA, Coles LS: Cold shock domain factors activate the granulocyte-macrophage colony-stimulating factor promoter in stimulated jurkat T cells. J Biol Chem 2001, 276:7943-7951.

9. Didier DK, Schiffenbauer J, Woulfe SL, Zacheis M, Schwartz BD: Characterization of the CDNA encoding a protein binding to the major histocompatibility complex class II Y box. Proc Natl Acad Sci U S A 1988, 85:7322-7326.

10. Bargou RC, Jurchott $K$, Wagener $C$, Bergmann $S$, Metzner $S$, Bommert $K$, Mapara MY, Winzer KJ, Dietel M, Dorken B, Royer HD: Nuclear localization and increased levels of transcription factor YB-1 in primary human breast cancers are associated with intrinsic MDR1 gene expression. Nat Med 1997, 3:447-450.

11. Mertens PR, Harendza S, Pollock AS, Lovett DH: Glomerular mesangial cellspecific transactivation of matrix metalloproteinase 2 transcription is mediated by YB-1. J Biol Chem 1997, 272:22905-22912.

12. Capowski EE, Esnault S, Bhattacharya S, Malter JS: Y box-binding factor promotes eosinophil survival by stabilizing granulocyte-macrophage colony-stimulating factor mRNA. J Immunol 2001, 167:5970-5976.

13. Skalweit A, Doller A, Huth A, Kahne T, Persson PB, Thiele BJ: Posttranscriptional control of renin synthesis: identification of proteins interacting with renin mRNA 3'-untranslated region. Circ Res 2003, 92:419-427.

14. Skabkin MA, Kiselyova Ol, Chernov KG, Sorokin AV, Dubrovin EV, Yaminsky IV, Vasiliev VD, Ovchinnikov LP: Structural organization of mRNA complexes with major core mRNP protein YB-1. Nucleic Acids Res 2004, 32:5621-5635.

15. Evdokimova V, Ruzanov P, Imataka H, Raught B, Svitkin Y, Ovchinnikov LP, Sonenberg N: The major mRNA-associated protein YB-1 is a potent $5^{\prime}$ cap-dependent mRNA stabilizer. Embo J 2001, 20:5491-5502.

16. Fraser DJ, Phillips AO, Zhang $X$, van Roeyen $C R$, Muehlenberg $P$, En-Nia A, Mertens PR: Y-box protein-1 controls transforming growth factor-beta1 translation in proximal tubular cells. Kidney international 2008, 73:724-732.

17. Raffetseder U, Frye B, Rauen T, Jurchott K, Royer HD, Jansen PL, Mertens PR: Splicing factor SRp30c interaction with Y-box protein-1 confers nuclear YB-1 shuttling and alternative splice site selection. J Biol Chem 2003, 278:18241-18248.

18. Cartwright $\mathrm{P}$, Helin K: Nucleocytoplasmic shuttling of transcription factors. Cell Mol Life Sci 2000, 57:1193-1206.

19. Stein U, Jurchott K, Walther W, Bergmann S, Schlag PM, Royer HD: Hyperthermia-induced nuclear translocation of transcription factor YB-1 leads to enhanced expression of multidrug resistance-related $A B C$ transporters. J Biol Chem 2001, 276:28562-28569.

20. Ohga T, Koike $K$, Ono M, Makino Y, Itagaki Y, Tanimoto M, Kuwano M, Kohno K: Role of the human Y box-binding protein YB-1 in cellular sensitivity to the DNA-damaging agents cisplatin, mitomycin C, and ultraviolet light. Cancer Res 1996, 56:4224-4228.

21. Tsujimura S, Saito K, Nakayamada S, Nakano K, Tsukada J, Kohno K, Tanaka $Y$ : Transcriptional regulation of multidrug resistance-1 gene by interleukin-2 in lymphocytes. Genes Cells 2004, 9:1265-1273.

22. Dooley S, Said HM, Gressner AM, Floege J, En-Nia A, Mertens PR: Y-box protein-1 is the crucial mediator of antifibrotic interferon-gamma effects. J Biol Chem 2006, 281:1784-1795. 
23. Oda Y, Ohishi Y, Saito T, Hinoshita E, Uchiumi T, Kinukawa N, Iwamoto $Y$, Kohno K, Kuwano M, Tsuneyoshi M: Nuclear expression of Y-box-binding protein-1 correlates with P-glycoprotein and topoisomerase II alpha expression, and with poor prognosis in synovial sarcoma. J Pathol 2003, 199:251-258.

24. Gessner C, Woischwill C, Schumacher A, Liebers U, Kuhn H, Stiehl P, Jurchott K, Royer HD, Witt C, Wolff G: Nuclear YB-1 expression as a negative prognostic marker in nonsmall cell lung cancer. Eur Respir J 2004, 23:14-19.

25. Janz M, Harbeck N, Dettmar P, Berger U, Schmidt A, Jurchott K, Schmitt M, Royer HD: Y-box factor YB-1 predicts drug resistance and patient outcome in breast cancer independent of clinically relevant tumor biologic factors HER2, uPA and PAI-1. Int J Cancer 2002, 97:278-282.

26. Gimenez-Bonafe $P$, Fedoruk MN, Whitmore TG, Akbari M, Ralph JL, Ettinger S, Gleave ME, Nelson CC: YB-1 is upregulated during prostate cancer tumor progression and increases P-glycoprotein activity. Prostate 2004, 59:337-349.

27. Geier A, Mertens PR, Gerloff T, Dietrich CG, En-Nia A, Kullak-Ublick GA, Karpen SJ, Matern S, Gartung C: Constitutive rat multidrug-resistance protein 2 gene transcription is down-regulated by Y-box protein 1. Biochem Biophys Res Commun 2003, 309:612-618.

28. Nakai K, Horton P: PSORT: a program for detecting sorting signals in proteins and predicting their subcellular localization. Trends Biochem Sci 1999, 24:34-36.

29. Bader AG, Vogt PK: Inhibition of protein synthesis by $Y$ box-binding protein 1 blocks oncogenic cell transformation. Mol Cell Biol 2005, 25:2095-2106.

30. Raffetseder U, Rauen T, Djudjaj S, Kretzler M, En-Nia A, Tacke F, Zimmermann HW, Nelson PJ, Frye BC, Floege J, et al: Differential regulation of chemokine CCL5 expression in monocytes/macrophages and renal cells by Y-box protein-1. Kidney international 2009, 75:185-196.

31. la Cour T, Gupta R, Rapacki K, Skriver K, Poulsen FM, Brunak S: NESbase version 1.0: a database of nuclear export signals. Nucleic Acids Res 2003, 31:393-396.

32. Ruzanov PV, Evdokimova VM, Korneeva NL, Hershey JW, Ovchinnikov LP: Interaction of the universal mRNA-binding protein, p50, with actin: a possible link between mRNA and microfilaments. J Cell Sci 1999, 112(Pt 20):3487-3496.

33. Sorokin AV, Selyutina AA, Skabkin MA, Guryanov SG, Nazimov IV, Richard C, Th'ng J, Yau J, Sorensen PH, Ovchinnikov LP, Evdokimova V: Proteasomemediated cleavage of the Y-box-binding protein 1 is linked to DNA damage stress response. Embo J 2005, 24:3602-3612.

34. Stenina OI, Shaneyfelt KM, DiCorleto PE: Thrombin induces the release of the $Y$-box protein $\mathrm{dbpB}$ from mRNA: a mechanism of transcriptional activation. Proc Natl Acad Sci U S A 2001, 98:7277-7282.

35. Harendza S, Pollock AS, Mertens PR, Lovett DH: Tissue-specific enhancerpromoter interactions regulate high level constitutive expression of matrix metalloproteinase 2 by glomerular mesangial cells. J Biol Chem 1995, 270:18786-18796.

36. Mertens PR, Alfonso-Jaume MA, Steinmann K, Lovett DH: A synergistic interaction of transcription factors $\mathrm{AP} 2$ and $\mathrm{YB}-1$ regulates gelatinase a enhancer-dependent transcription. J Biol Chem 1998, 273:32957-32965.

37. Norman JT, Lindahl GE, Shakib K, En-Nia A, Yilmaz E, Mertens PR: The Y-box binding protein $\mathrm{YB}-1$ suppresses collagen alpha $1(\mathrm{I})$ gene transcription via an evolutionarily conserved regulatory element in the proximal promoter. J Biol Chem 2001, 276:29880-29890.

38. Izumi H, Imamura T, Nagatani G, Ise T, Murakami T, Uramoto H, Torigoe T, Ishiguchi H, Yoshida $Y$, Nomoto $M$, et al: $Y$ box-binding protein-1 binds preferentially to single-stranded nucleic acids and exhibits $3^{\prime} \rightarrow 5^{\prime}$ exonuclease activity. Nucleic Acids Res 2001, 29:1200-1207.

39. van Roeyen CR, Eitner F, Martinkus S, Thieltges SR, Ostendorf T, Bokemeyer D, Luscher B, Luscher-Firzlaff JM, Floege J, Mertens PR: Y-box protein 1 mediates PDGF-B effects in mesangioproliferative glomerular disease. J Am Soc Nephrol 2005, 16:2985-2996.

40. Rauen T, Raffetseder U, Frye BC, Djudjaj S, Muhlenberg PJ, Eitner F, Lendahl U, Bernhagen J, Dooley S, Mertens PR: YB-1 acts as a ligand for notch-3 receptors and modulates receptor activation. J Biol Chem 2009, 284:26928-26940.

41. Frye BC, Halfter S, Djudjaj S, Muehlenberg P, Weber S, Raffetseder U, En-Nia A, Knott H, Baron JM, Dooley S, et al: Y-box protein-1 is actively secreted through a non-classical pathway and acts as an extracellular mitogen. EMBO reports 2009, 10:783-789.

42. Hornbeck PV, Kornhauser JM, Tkachev S, Zhang B, Skrzypek E, Murray B, Latham V, Sullivan M: PhosphoSitePlus: a comprehensive resource for investigating the structure and function of experimentally determined post-translational modifications in man and mouse. Nucleic Acids Res 2012, 40:D261-D270

43. Lutz M, Wempe F, Bahr I, Zopf D, von Melchner H: Proteasomal degradation of the multifunctional regulator YB-1 is mediated by an F-Box protein induced during programmed cell death. FEBS letters 2006, 580:3921-3930.

44. Cohen SB, Ma W, Valova VA, Algie M, Harfoot R, Woolley AG, Robinson PJ, Braithwaite AW: Genotoxic stress-induced nuclear localization of oncoprotein YB-1 in the absence of proteolytic processing. Oncogene 2010, 29:403-410.

45. Woolley AG, Algie M, Samuel W, Harfoot R, Wiles A, Hung NA, Tan PH, Hains $P$, Valova VA, Huschtscha L, et al: Prognostic association of YB-1 expression in breast cancers: a matter of antibody. PLoS One 2011, 6:e20603.

46. Ladomery M, Sommerville J: Binding of Y-box proteins to RNA: involvement of different protein domains. Nucleic Acids Res 1994, 22:5582-5589.

47. Sommerville J, Ladomery M: Masking of mRNA by Y-box proteins. FASEB J 1996, 10:435-443.

48. Jurchott K, Kuban RJ, Krech T, Bluthgen N, Stein U, Walther W, Friese C, Kielbasa SM, Ungethum U, Lund P, et al: Identification of Y-box binding protein 1 as a core regulator of MEK/ERK pathway-dependent gene signatures in colorectal cancer cells. PLoS Genet 2010, 6:e1001231.

49. Lasham A, Print CG, Woolley AG, Dunn SE, Braithwaite AW: YB-1: oncoprotein, prognostic marker and therapeutic target? Biochem J 2013, 449:11-23.

50. Neubert K, Meister S, Moser K, Weisel F, Maseda D, Amann K, Wiethe C, Winkler TH, Kalden JR, Manz RA, Voll RE: The proteasome inhibitor bortezomib depletes plasma cells and protects mice with lupus-like disease from nephritis. Nat Med 2008, 14:748-755.

51. Bontscho J, Schreiber A, Manz RA, Schneider W, Luft FC, Kettritz R: Myeloperoxidase-specific plasma cell depletion by bortezomib protects from anti-neutrophil cytoplasmic autoantibodies-induced glomerulonephritis. J Am Soc Nephrol 2011, 22:336-348.

52. Mertens PR, Espenkott V, Venjakob B, Heintz B, Handt S, Sieberth HG: Pressure oscillation regulates human mesangial cell growth and collagen synthesis. Hypertension 1998, 32:945-952.

53. Reisdorff J, En-Nia A, Stefanidis I, Floege J, Lovett DH, Mertens PR: Transcription factor Ets-1 regulates gelatinase a gene expression in mesangial cells. J Am Soc Nephrol 2002, 13:1568-1578.

54. Mertens PR, Alfonso-Jaume MA, Steinmann K, Lovett DH: YB-1 regulation of the human and rat gelatinase $A$ genes via similar enhancer elements. J Am Soc Nephrol 1999, 10:2480-2487.

55. Hanssen L, Frye BC, Ostendorf T, Alidousty C, Djudjaj S, Boor P, Rauen T, Floege J, Mertens PR, Raffetseder U: Y-box binding protein-1 mediates profibrotic effects of calcineurin inhibitors in the kidney. J Immunol 2011, 187:298-308.

\section{doi:10.1186/1478-811X-11-63}

Cite this article as: van Roeyen et al:: Cold shock Y-box protein-1 proteolysis autoregulates its transcriptional activities. Cell Communication and Signaling 2013 11:63. 